\title{
BMJ Open From first symptoms to diagnosis of amyotrophic lateral sclerosis: perspectives of an Irish informal caregiver cohort-a thematic analysis
}

\author{
Miriam Galvin, ${ }^{1}$ Rebecca Gaffney, ${ }^{1}$ Bernie Corr, ${ }^{2}$ Iain Mays, ${ }^{1}$ Orla Hardiman ${ }^{1,2}$
}

To cite: Galvin M, Gaffney R, Corr B, et al. From first symptoms to diagnosis of amyotrophic lateral sclerosis: perspectives of an Irish informal caregiver cohort-a thematic analysis. BMJ Open 2017;7:e014985. doi:10.1136/bmjopen-2016014985

- Prepublication history for this paper is available online. To view these files please visit the journal online (http://dx.doi.org/10.1136/ bmjopen-2016-014985).

Received 31 October 2016 Revised 23 December 2016 Accepted 19 January 2017

CrossMark

\begin{abstract}
${ }^{1}$ Academic Unit of Neurology, Trinity Biomedical Sciences Institute, Trinity College Dublin, Dublin 2, Ireland 2Department of Neurology, National Neuroscience Centre, Beaumont Hospital, Dublin 9, Ireland
\end{abstract}

Correspondence to Dr Miriam Galvin; galvinmi@tcd.ie

\section{ABSTRACT}

Objectives: Informal caregivers play an integral part in the management of amyotrophic lateral sclerosis (ALS). The objective of this study was to explore the journey from first problem symptoms to diagnosis from the perspective of informal caregivers providing care to people with ALS.

Design: As part of a semistructured interview, information was collected on a range of caregiver demographic details, and from an open-ended question their experiences of the time of symptom onset to diagnosis. We carried out descriptive statistical analysis and thematic analysis of qualitative data.

Setting and participants: Home interviews with informal caregivers $(n=74)$ of people with ALS attending the National ALS/Motor Neuron Disease Clinic at Beaumont Hospital, Dublin, Ireland.

Results: This was a largely female and spousal cohort of caregivers, living with the patient for whom they provided informal care. The majority of patients were men and were spinal onset. Caregivers described the time from first symptoms to diagnosis. Using a primarily inductive approach, the coding was data driven and the codes and themes derived from the content of these descriptions. Two main themes were identified (1) problem signs and symptoms (A) noticing and (B) reaction; (2) interaction with the health services. Conclusions: Exploring the perspectives of caregivers from first problem symptoms to diagnosis provides valuable insights into the development of the condition, impediments to its recognition, help-seeking behaviours and interactions with healthcare services. The journey from early symptoms to diagnosis is important for future decision-making, affects readiness for caregiving and could negatively impact on caregiver health and well-being. The early acknowledgement by healthcare professionals of stressors along the journey to diagnosis, and appreciation of their possible impact on caregivers is important. The separate needs of caregivers should be assessed on a regular basis.

\section{INTRODUCTION}

Amyotrophic lateral sclerosis (ALS) also known as motor neuron disease (MND) is a

\section{Strengths and limitations of this study}

- Informal caregivers describe the time from first symptoms to diagnosis of amyotrophic lateral sclerosis.

- The caregivers' perspectives provide valuable insights into the practical and psychosocial issues on the journey to diagnosis.

- Using an inductive approach the themes identified were derived from the data.

- Descriptions were provided in response to one open-ended question in a largely quantitative interview which limited the opportunity to expand on their experiences.

- It is important to explore experiences before diagnosis and the quality of these experiences through in-depth interviews with caregivers.

progressive neurodegenerative condition which results in loss of physical function due to the degeneration of upper and lower motor neurons. Up to $50 \%$ of patients with ALS develop a degree of cognitive impairment. ${ }^{1}$ There are currently no effective disease-modifying therapies, management is symptomatic, and $70 \%$ of those affected die within 3 years of symptom onset. ${ }^{2}$ In the Republic of Ireland, there are $\sim 300$ prevalent ALS cases and 110 new diagnoses each year. ${ }^{3}$ At least $80 \%$ of all patients within Ireland attend the National ALS/MND Clinic at Beaumont Hospital, Dublin.

Informal caregivers play an integral part in the management of ALS with family and friends taking most of the responsibility. They are key figures in care provision, provide emotional and physical support for patients and often play a central role in clinical decision-making. ${ }^{4-6}$

Symptoms and site of onset

ALS onset is generally classified as being bulbar, spinal or respiratory, with a proportion 
of patients presenting with cognitive and/or behavioural impairment. In the bulbar form of ALS, the muscles used for speaking, swallowing and breathing are affected. It is usually characterised by slurring of words, impaired tongue movements and difficulty swallowing. Patients with spinal/limb onset experience fine-motor disturbances and paralyses in the arms and legs, presenting symptoms usually include weakness and/or wasting in the leg and arm muscles and fasciculation. Respiratory onset is characterised by breathing difficulties and shortness of breath. $^{7}$

\section{Diagnosis}

A diagnosis of ALS is primarily based on the physician's interpretation of clinical symptoms and signs, in addition to investigations to exclude other causes. ${ }^{8}$ ALS diagnostic timelines have remained consistent over a 20-year period (1998-2008), time from first symptom to diagnosis is a median 12 months. ${ }^{9}$ Earlier diagnosis can enable more effective symptom management and care planning. Diagnostic delays in ALS are associated with clinical complexity, the patient either not recognising or denying early or intermittent symptoms, inefficient referral pathways, the relative rarity and the consequent lack of familiarity with the condition among general healthcare professionals (HCPs). ${ }^{8}$ General practitioners will only see one or two cases throughout their career. ${ }^{7}$ Delays in diagnosis can account for a significant proportion of total illness duration. This can represent a missed opportunity to start treatment with riluzole, the only disease-modifying therapy at present. It may also prohibit patients from enrolling in clinical trials at an early stage of disease, when the likelihood of benefiting from experimental treatments might be greater. ${ }^{10}$ Delays also impede referral to multidisciplinary clinics (MDCs), which can improve patient outcomes both with respect to survival and quality of life. ${ }^{3}{ }^{11}$ Findings from an exploratory study noted a mean interval of 19 months (median 14.6) from first symptoms to arrival at an ALS MDC, and an average of four contacts with HCPs. ${ }^{12}$

\section{Help seeking}

The general public has a poor understanding of $\mathrm{ALS}^{13}$ and it is often the case that patients and/or caregivers are slow to seek medical advice. Symptoms may be noticed but medical help is not sought if symptoms are not severe, with alternative reasons considered reasons for their difficulties. O'Brien $e t a l^{4}$ found that the initial symptoms were regularly not recognised by patients, family members and health professionals, which delayed seeking medical attention and resulted in delayed diagnosis.

\section{Aim}

The aim of this analysis was to explore the journey from first problem symptoms to diagnosis from the perspective of informal caregivers providing care to people with ALS.
METHODS

\section{Participants}

Participants were consecutively recruited as primary informal caregivers of patients taking part in a longitudinal study of the patient and caregiver journey though ALS/MND, attending the specialist multidisciplinary National ALS/MND Centre at Beaumont Hospital, Dublin. Caregiver participants were identified by the person with ALS as his/her primary informal caregiver, providing unpaid care and assistance to them.

Caregivers were approached by a research assistant (IM) during clinic visits, and were provided with information about the research study. This initial contact was followed up by telephone to establish their interest and consent to participate. Informed written consent was obtained from all participants at the time of interview. Eighty-eight caregivers were recruited to the study, 14 did not complete an open-ended question regarding the time from first symptoms to diagnosis. This analysis is based on data from 74 caregivers who responded to that question.

\section{Data collection}

During a pilot-tested, semistructured interview, information was collected on a range of demographic and socioeconomic factors. In an open-ended question, caregivers were asked about their experiences from the time of symptom onset to diagnosis. This question was formulated through group discussions with senior and experienced members of the clinical staff working as part of the multidisciplinary service for patients with ALS/ MND. Patients' clinical details were available through the National ALS Register, for which they had consented to inclusion of their codified clinical and demographic data.

Interviews took place between May 2013 and November 2014. The face-to-face interviews with only the interviewer and participant present, lasted $\sim 1$ hour and were conducted in the caregiver's own home by a male assistant psychologist (IM) or a female health services researcher (MG) both members of the research team. Responses to the open-ended questions, and any related field notes were recorded in written format by the interviewer.

\section{Data analysis}

Descriptive statistics summarised demographic, socioeconomic and clinical data. Thematic analysis, chosen as a theoretically flexible method, was used to identify patterns in the data and themes for analysis. ${ }^{15}$ From a critical realist perspective, and employing an inductive approach, the themes identified on a semantic level were closely linked to the data. Multiple coders (RG, IM and MG) took part in a multiphase process including initial coding, theme development, review and definition. ${ }^{15}$ Audit trails were developed using reflexive memos and codebooks. The codes generated and themes constructed were reviewed and credibility of 
findings was established based on clinical experience (BC). There was discussion on points of agreement/ disagreement leading to consensual validation. Data analysis software NVivo V.10 (QSR International, NVivo qualitative data analysis software; QSR International Pty Ltd version 10, 2012) was used to collate and manage the qualitative data, record coding patterns and theme development.

\section{RESULTS}

\section{Caregiver characteristics: descriptive statistical analysis}

Table 1 summarises the characteristics of caregivers and the patients for whom they provided care.

A majority of the caregiver cohort was women $69 \%$ $(\mathrm{n}=51)$. The mean age was 55.7 years (SD 12.8 years) ranging from 25 to 76 years. Predominantly caregivers were family members, $72 \% \quad(n=53)$ were a spouse/ partner, $20 \%$ son or daughter, and $4 \%$ a sibling of a person with ALS. Eighty-one per cent $(n=60)$ were living with the person with ALS.

Forty-three per cent of caregivers were working for payment or profit at the time of interview, while $47 \%$ were either retired or looking after family/home. Over half $(53 \%)$ indicated that they had health problems, longterm illness or disability, for example, asthma, blood pressure, diabetes and heart condition. Notwithstanding $81 \%$ rated that their own health was good, very good or excellent.

Sixty-one per cent of patients were men, with a mean age of 65 years (SD 9.7 years), ranging from 43 to 87 years. Distribution of patients by site of onset showed the majority were spinal onset $(69 \%)$, bulbar onset $(28 \%)$ and thoracic/respiratory (3\%; figure 1). The time from symptom onset to ALS diagnosis ranged from 1 month to 4.7 years (mean 15.7 months, SD 11.04), median 12 months (IQR 8-22), a mean 13.2 months (median 11) for bulbar onset, mean of 17 months (median 12) for spinal onset and respiratory onset with a mean of 10 months (median 10).

Using data from the National ALS/MND Patient Register, the time in months from first symptoms to diagnosis for each patient in ascending order, and the site of onset is illustrated in figure 1.

\section{Thematic analysis}

In an open-ended question, caregivers were asked to think about the time when the patient first started having problems up to diagnosis.

Thinking of the time when [ ] first started having problems up to his/her diagnosis with MND, what was that time like for you?

Through a thematic analysis two main themes and component subthemes were developed and are presented here: (1) problems and symptoms (A) noticing

\begin{tabular}{|c|c|c|}
\hline \multicolumn{3}{|l|}{ Caregivers $(n=74)$} \\
\hline \multicolumn{3}{|l|}{ Age } \\
\hline Mean & \multicolumn{2}{|c|}{55.7 (SD 12.82) } \\
\hline Range & \multicolumn{2}{|c|}{$25-76$ years } \\
\hline \multicolumn{3}{|l|}{ Sex } \\
\hline Male & 23 & $31.1 \%$ \\
\hline Female & 51 & $68.9 \%$ \\
\hline \multicolumn{3}{|l|}{ Relationship to the patient } \\
\hline Spouse/partner & 53 & $71.6 \%$ \\
\hline Son/daughter & 15 & $20.3 \%$ \\
\hline Parent & 2 & $2.7 \%$ \\
\hline Sibling & 3 & $4.1 \%$ \\
\hline Friend & 1 & $1.4 \%$ \\
\hline \multicolumn{3}{|l|}{ Lives with patient } \\
\hline Yes & 60 & $81.1 \%$ \\
\hline No & 14 & $18.9 \%$ \\
\hline \multicolumn{3}{|l|}{ Principal economic status } \\
\hline Working for payment or profit & 32 & $43.2 \%$ \\
\hline Unemployed & 4 & $5.4 \%$ \\
\hline Looking after family/home & 16 & $21.6 \%$ \\
\hline Retired & 19 & $25.7 \%$ \\
\hline $\begin{array}{l}\text { Unable to work due to } \\
\text { permanent sickness or } \\
\text { disability }\end{array}$ & 3 & $4.1 \%$ \\
\hline \multicolumn{3}{|c|}{ In general, would you say your health is } \\
\hline Excellent & 14 & $18.9 \%$ \\
\hline Very good & 20 & $27.0 \%$ \\
\hline Good & 26 & $35.1 \%$ \\
\hline Fair & 9 & $12.2 \%$ \\
\hline Poor & 5 & $6.8 \%$ \\
\hline \multicolumn{3}{|c|}{$\begin{array}{l}\text { Do you have any long-term illness, health problems or } \\
\text { disability? }\end{array}$} \\
\hline Yes & 39 & $52.7 \%$ \\
\hline No & 35 & $47.3 \%$ \\
\hline \multicolumn{3}{|l|}{ Patients $(n=74)$} \\
\hline \multicolumn{3}{|l|}{ Age } \\
\hline Mean & \multicolumn{2}{|c|}{65.16 (SD 9.74) } \\
\hline Range & \multicolumn{2}{|c|}{$43-87$ years } \\
\hline \multicolumn{3}{|l|}{ Sex } \\
\hline Male & 45 & $60.8 \%$ \\
\hline Female & 29 & $39.2 \%$ \\
\hline \multicolumn{3}{|l|}{ Site of onset } \\
\hline Bulbar & 21 & $28.4 \%$ \\
\hline Spinal & 51 & $68.9 \%$ \\
\hline Thoracic/respiratory & 2 & $2.7 \%$ \\
\hline \multicolumn{3}{|c|}{ Time from symptom onset to diagnosis } \\
\hline Mean (months) & $\begin{array}{l}15.7 \\
110\end{array}$ & \\
\hline Range & $1-5$ & \\
\hline Median & 12 & \\
\hline IQR & $8-2$ & \\
\hline
\end{tabular}

and (B) reaction and response and (2) interactions with healthcare services (figure 2).

These themes with selected supporting quotes are presented below, denoted by caregiver ID and relationship to patient (eg, \#1cg, wife) and site of ALS onset (eg, spinal onset). 


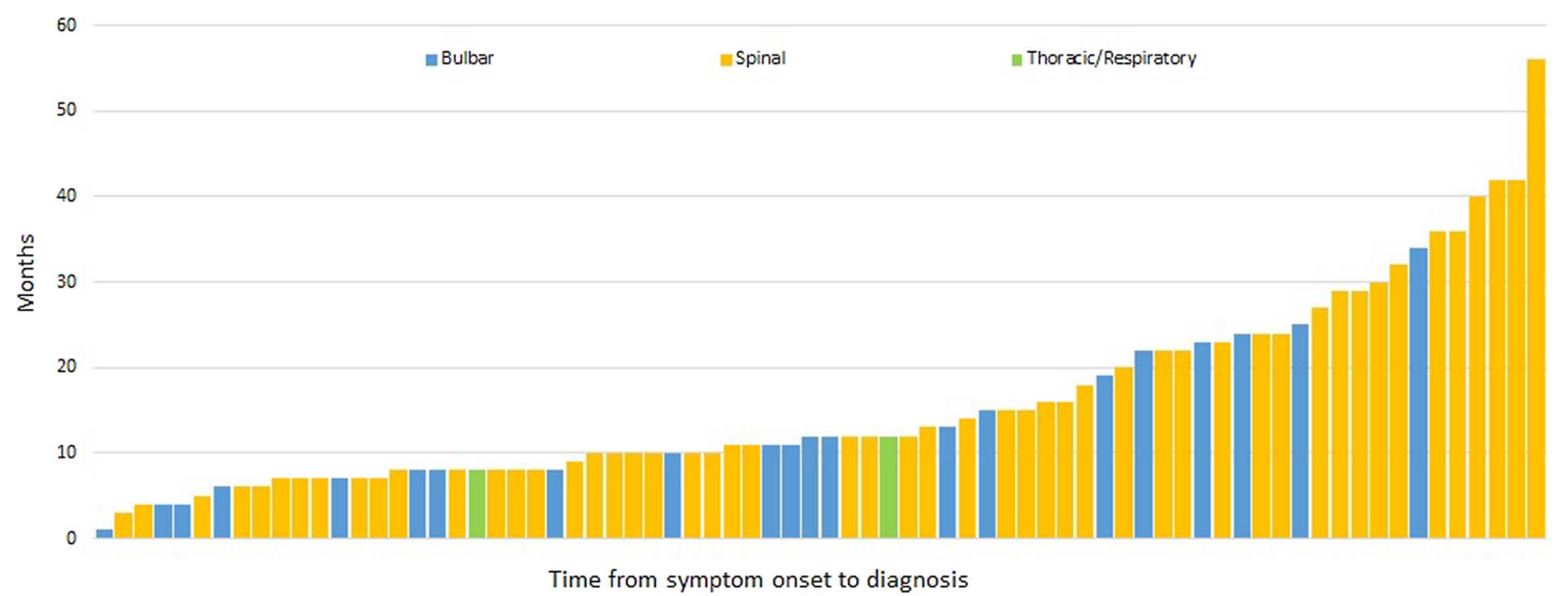

Figure 1 Time (months) from first symptoms to diagnosis and site of onset.

\section{Theme 1: problems and symptoms: noticing and reaction and response \\ Noticing problems/symptoms}

Various problem signs and symptoms were described. There were instances of voice distortion, falling, twitching limbs, problems with slurred speech and eating. Respondents described noticing something was wrong and began attributing meaning to symptoms, for some this occurred gradually over time.

Limb weakness meant problems with walking and daily tasks became noticeable:

It started with a twitch in his arm, we never thought it was this. He said 'I can't walk in a straight line. (56cg wife, spinal onset)

Probably with the hands, not being able to open things or turn keys or cook. (98cg son, spinal-cognitive/behavioural onset)

Some caregivers described not noticing problem signs which were brought to their attention by other family members and friends:

I didn't even notice it, my daughter noticed her speech was going. (48cg sister, bulbar onset)

It wouldn't be the family that noticed it would be family-in-law, wife or brother or sister-in law, slurring words, fatigue and open mouth. (92cg son, bulbar onset)

Problems noticed were attributed by them to factors such as poorly fitting dentures, and conditions related to heart problems, arthritis, carpal tunnel syndrome, stress or stroke. Looking back, and from what they now know, caregivers could connect what were diverse symptoms at the time.

Noticing symptoms, not noticing, misattribution to another condition and gradual evolution of symptoms was summed up by one caregiver:
You could see a little bit of a problem, it was hard for me to notice, it was my sister in England who noticed; my sister thought she had a stroke; once she got the second set of teeth done we thought well there was something bad with her. Looking back she's been suffering for a few years, for example there's been twitching in her legs for 4-5 years or there was a fall from a ladder a year and a half ago. (94cg son, bulbar onset)

\section{Reaction and response}

When problems were noticed caregivers described a variety of psychoemotional and practical reactions and responses. The range of psychoemotional reactions included worry, denial, anxiety, uncertainty, annoyance, frustration, panic, fear, disbelief, suspicion, misattribution, annoyance and avoidance. More focused practical responses included searching for information and advice and attempts to link with healthcare services.

These future caregivers were situated in their own domestic contexts, trying to cope with what was happening, balance other responsibilities and possible adjustment to their own lives:

I was struggling with my own life as well. I was doing everything and anything to help and do things and prevent her from falling; so it got to the stage where I couldn't leave her side; it was quite stressful, I was trying to hold a relationship, job and caring for mum... $(99 \mathrm{cg}$ daughter, spinal onset)

For some there was disbelief as they could not understand what was happening around them: "I thought 'maybe I'm nuts', my two friends checked, and said 'you're not seeing things" (54cg wife, spinal onset) or that perhaps the patient was imagining symptoms. Conversely, other caregivers found themselves trying to convince other people, at times including the patient: "I think I was the only one that noticed the speech problems. I kept saying it and he [patient] said it was his teeth" (68cg wife, bulbar onset). 


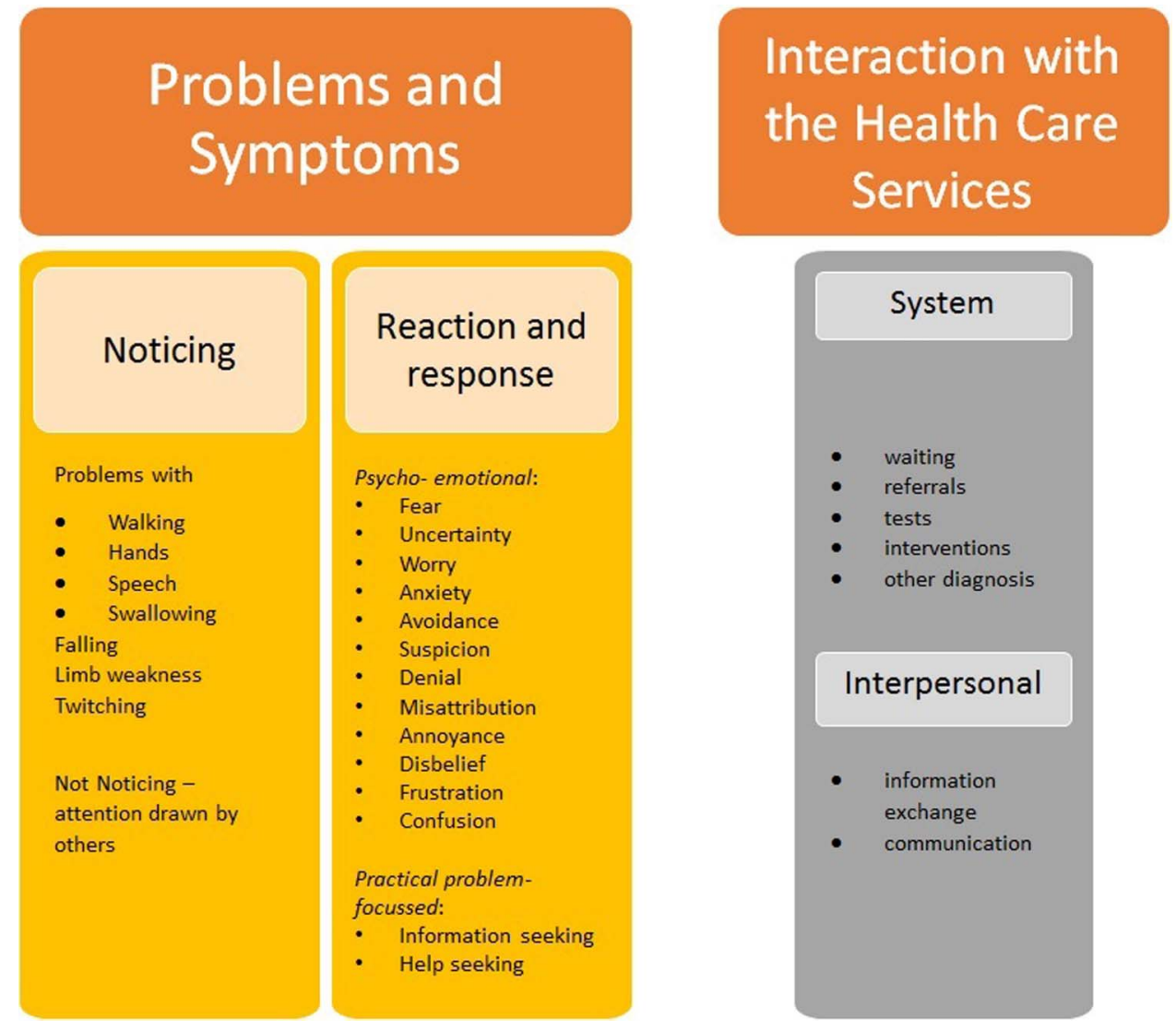

Figure 2 Themes and subthemes.

There was confusion and uncertainty with the realisation that something was wrong but "we couldn't find out what." Fear was commonly described, fear of the unknown or what symptoms could mean, fear of not being able to cope or manage to provide care in the future. There was also awareness that the problems were indicative of something serious. Some who suspected there was something seriously wrong described avoidance and denial in various forms in an effort to "block it out' or redirect their thoughts and focus: "Running and exercising until you didn't have to think about it was important for me to function" (49cg wife, spinal onset).

There was a degree of desperate hoping and wishful thinking: "[patient] said 'I hope it's not MS', I said 'I hope it's not MND'. By saying that I thought 'well, it won't be that because that could be the worst thing'" (42cg wife, spinal onset).

One month before diagnosis I questioned the possibility [patient] had MND but ruled it out as friend's husband previously had condition and didn't think it would strike twice. (26cg wife, bulbar onset)

There were also practical problem-focused responses, as they sought a diagnosis, and were proactive in seeking advice and information, even if it was difficult to face what that could mean. Caregivers commonly encouraged the patient to seek medical advice, which was accompanied by irritation and frustration when the patient would not do so:

He wasn't going to the doctor and I made him go. I knew there was something wrong. I didn't know what it was, I hadn't a clue to be honest. I used to get annoyed about him not going to the doctor. (70 g wife, spinal onset)

Other people described the patient not complaining, and guarding his/her privacy as they chose not to disclose what was happening around this time:

I didn't feel involved at all...The patient was going and seeing to himself and didn't feel the need to bother me. He had broken an arm and we thought it was that. I had little worry as I didn't know. (71cg wife, spinal onset)

She kept a lot to herself and didn't tell us about much of the tests. (91cg sister, bulbar onset)

\section{Theme 2: interaction with healthcare services}

Interaction with the healthcare services featured from the time of first symptoms up to diagnosis. This included attempts to convince the patient to seek medical advice, referrals across the health system and engagement with HCPs. Fear, worry, anger and frustration were again present in the responses, as caregivers described referral routes, tests and interventions and perceived misdiagnoses. 
In response to noticing symptoms caregivers sought information and advice. It sometimes proved difficult to get to see specialist physicians, while succeeding in obtaining an appointment with a specialist did not mean an end to the uncertainty, anxiety or fear. For many, it had been a struggle to persuade the patient to seek medical advice. When they had begun that process, caregivers and patients made their way through various tests and interventions, for example, back operation, and were referred to health practitioners such as physiotherapist, ear, nose and throat physician and neurologist, on the journey to a definitive diagnosis.

Some respondents felt that they and the patients were not listened to, and they could not understand the medical decisions and information received, adding to the confusion and uncertainty experienced:

The doctors said I was being overprotective and as a last resort they sent us to a speech and language therapist and the speech and language therapist referred us to Consultant Neurologist; now we had doctors do an MRI in [clinic name], they came back and said nothing was wrong. (100 cg husband, bulbar onset)

There were perceived misdiagnoses of the presenting symptoms: "A lot was missed that has been spotted now. First went to physio, then neurologist about her migraines. The doctor said it wasn't neurological, it was mechanical. The neurologist apologised in the end" (55cg husband, spinal onset).

According to respondents, other diagnoses made by HCPs included stroke, myasthenia gravis or 'unknown'. With various diagnoses and none, caregivers found themselves in a difficult position as medical opinion offered did not seem to fit with their experiences:

I was relieved she went to the doctor, but was sceptical when the doctors said she had a fine bill of health in the hospital. We thought it was a stroke as it was in the family. Those connections and evidence were there it just didn't feel right... (92cg son, bulbar onset)

The ways in which caregivers (and patients) experienced communication and received information from the HCPs, how tests and referrals were discussed, and diagnoses communicated was less than optimal for many. Respondents described various encounters when information was delivered and communicated to them by HCPs. The quotes below illustrate some of these experiences:

The first doctor didn't highlight what he was doing, because we flew through a lot of tests we thought this was a good thing, one day I got a call from [patient] and he mentioned the doctor had asked an MND question and I was like 'where did that come from?'. It could have been signposted a bit better. ( $7 \mathrm{cg}$ wife, spinal-cognitive onset)

(Neurologist) did neurological tests. Stressful time. Left [patient] sitting in his underpants for like 10 minutes by consultant who took a phone call! (second neurologist) ...said I would lay my bet on MND then went out the door. (12cg wife, spinal)

\section{DISCUSSION}

The diagnosis of a terminal illness can have a dramatic impact on the lives of family members, many of whom will become caregivers. Caregivers' descriptions of the time from noticing the first problems to diagnosis are recollections of that time, related events and feelings. These recollections may differ from what occurred, nevertheless they are experiential and meaning-filled, and shape current and future experiences and the meanings attached to them.

The majority of this cohort was women (69\%), and were family members $(99 \%)$ of the person with ALS. Forty-three per cent were working at the time of interview, and just over half indicated they had some health issues. Coming from individual precare contexts, caregivers described both noticing and failing to notice symptoms and engagement with health services.

Responding to problems and symptoms and how they were interpreted included suspicion, denial, avoidance, fear, confusion, worry and help-seeking. While many caregivers noticed and may not have understood what was happening, others denied any observations. Emotional and avoidance-focused coping are generally considered to be maladaptive. ${ }^{16}$ Avoidance-based coping may be beneficial and act as a protective factor in some situations; however, it becomes a problem when applied continuously. ${ }^{17}$ Patients and caregivers seek more information following communication of ALS diagnosis. ${ }^{18}$ The internet, family, friends and media were used as sources for information, from outside the healthcare system, during the prediagnosis phase.

There are physical, psychological, emotional and social challenges to the health and well-being of ALS caregivers. Caregiver stress leads to adverse outcomes, psychological distress and increased burden. ${ }^{19} 20$ The existence of elevated levels of anxiety from the prediagnosis phase should be incorporated into HCPs interpretation of caregiver burden. ${ }^{21}$ The findings from this study show psychological distress and burden present before diagnosis. The early acknowledgement by HCPs of stressors along the journey to diagnosis, and appreciation of their possible impact on the health and well-being of caregivers are crucial.

Many caregivers described a failure of the HCP at the first point of contact to recognise the gravity of the symptoms. Previous research ${ }^{8}$ has indicated the presence of a 'red flag' system for clinicians, as symptoms (eg, changes in speech, gait disturbance) warrant prompt referral to a neurologist. It is recommended that patients with symptoms suggestive of ALS should be assessed as soon as possible by an experienced neurologist, early diagnosis and investigations performed with high priority. The experiences of caregivers in this study 
reflects a series of issues at both personal and professional levels-inexperienced physicians, diagnostic uncertainty, the patient's refusal to seek help, and individual coping styles and strategies such as denial and avoidance. In many cases, the family had already endured a prolonged and frustrating journey to come to the point of engagement with health services. Once in the system, problems were encountered in accessing specialist medical opinion in a timely way, caregivers felt they (and patients) 'were passed around' that HCPs did not listen, or failed to recognise the seriousness of the condition, or misdiagnosed the symptoms. The interpersonal dynamics and communication from some HCPs were experienced as disrespectful, perfunctory and negative by some caregivers. Previous research points to communication difficulties with HCPs with respect to obtaining information about diagnosis and health status, and a lack of empathy and an absence of compassion conveyed by medical professionals. ${ }^{414}{ }^{18}$ Guidelines are available to assist in communication practices and educational programmes can be accessed to improve communication skills. $^{8142223}$

Clinicians communicate their expertise and experience with managing ALS, while patients, caregivers and family communicate their experiences of living with it. Our findings suggest the continued need for improvement in information exchange and communication between HCPs and patients and caregivers.

Caregivers play an important role in the healthcare ecosystem. Treating physicians should be aware of the importance of the caregiver-patient dyad and family environment in caring for patients with ALS. The ongoing and separate needs of caregivers should be assessed on a regular basis. It is important to recognise that the journey to diagnosis may impact the future caregiving course and subsequent engagement with health services.

This exploratory qualitative substudy is part of a large longitudinal primarily quantitative study. The caregiver descriptions were provided in response to one openended interview question, with limited opportunity to expand on their experiences. It will be important to explore the time before diagnosis and the quality of their experiences through in-depth interviews with caregivers.

\section{CONCLUSION}

Exploring the perspectives of caregivers from first problem symptoms to diagnosis provides valuable insights into the development of the condition, impediments to recognition of early signs and symptoms, helpseeking behaviours and interactions with the HCPs and services. The prediagnosis trajectory of care has the potential to negatively affect future caregivers, and may impact on the subsequent caregiving course. Family caregivers are important in ALS and are influential in the patient-caregiver dyad. HCPs need to recognise that caregivers may already be in a psychologically distressed state at the point of diagnosis, which could place them at increased risk of experiencing distress and burden from caregiving.

Acknowledgements The authors would like to thank the caregivers who participated in this research, Mark Heverin and Alice Vajda Research Managers and Sile Carney Research Assistant at the Academic Unit of Neurology, TCD.

Contributors MG designed and developed the study, analysed and interpreted the data. $M G$ and $R G$ drafted the initial manuscript. $B C$ was involved in the development of the research question and interpretation of the data. $R G$ and IM assisted with analysis, and interpretation of data, IM and MG was involved in the acquisition and interpretation of data. $\mathrm{MG}$ and $\mathrm{OH}$ revised the drafts for intellectual content and edited the manuscript. All authors reviewed and approved the final draft.

Funding This research was supported by funding from the Irish Health Research Board Dublin as part of the HRB Interdisciplinary Capacity Enhancement Awards.

Competing interests None declared.

Ethics approval Beaumont Hospital Ethics (Medical Research) Committee (REC REF 12/84) and the Research Ethics Committee, Trinity College Dublin.

Provenance and peer review Not commissioned; externally peer reviewed.

Data sharing statement No additional data are available.

Open Access This is an Open Access article distributed in accordance with the Creative Commons Attribution Non Commercial (CC BY-NC 4.0) license, which permits others to distribute, remix, adapt, build upon this work noncommercially, and license their derivative works on different terms, provided the original work is properly cited and the use is non-commercial. See: http:// creativecommons.org/licenses/by-nc/4.0/

\section{REFERENCES}

1. Elamin M, Bede P, Byrne S, et al. Cognitive changes predict functional decline in ALS: a population-based longitudinal study. Neurology 2013;80:1590-7.

2. Rooney J, Byrne S, Heverin M, et al. Survival analysis of Irish amyotrophic lateral sclerosis patients diagnosed from 1995-2010. PLOS ONE 2013;8:e74733.

3. Rooney J, Byrne S, Heverin M, et al. A multidisciplinary clinic approach improves survival in ALS: a comparative study of ALS in Ireland and Northern Ireland. J Neurol Neurosurg Psychiatry 2015;86:496-501.

4. Aoun SM, Connors SL, Priddis L, et al. Motor neurone disease family carers' experiences of caring, palliative care and bereavement: an exploratory qualitative study. Palliat Med 2012;26:842-50.

5. Aoun SM, Bentley B, Funk L, et al. A 10-year literature review of family caregiving for motor neurone disease: moving from caregiver burden studies to palliative care interventions. Palliat Med 2013;27:437-46.

6. Rabkin JG, Albert SM, Rowland LP, et al. How common is depression among ALS caregivers? A longitudinal study. Amyotroph Lateral Scler 2009;10:448-55.

7. McDermott CJ, Shaw PJ. Diagnosis and management of motor neurone disease. BMJ 2008;336:658-62.

8. Andersen PM, Abrahams S, Borasio GD, et al. EFNS guidelines on the Clinical Management of Amyotrophic Lateral Sclerosis (MALS) -revised report of an EFNS task force. Eur J Neurol 2012;19:360-E24.

9. Mitchell JD, Callagher P, Gardham J, et al. Timelines in the diagnostic evaluation of people with suspected amyotrophic lateral sclerosis (ALS)/motor neuron disease (MND)-a 20-year review: Can we do better? Amyotroph Lateral Scler 2010;11:537-41.

10. Paganoni S, Macklin EA, Lee A, et al. Diagnostic timelines and delays in diagnosing amyotrophic lateral sclerosis (ALS). Amyotroph Lateral Scler Frontotemporal Degener 2014;15:453-6.

11. Van den Berg JP, Kalmijn S, Lindeman E, et al. Multidisciplinary ALS care improves quality of life in patients with ALS. Neurology 2005;65:1264-7. 
12. Galvin M, Madden C, Maguire S, et al. Patient journey to a specialist amyotrophic lateral sclerosis multidisciplinary clinic: an exploratory study. BMC Health Serv Res 2015;15:571.

13. Davies Z, Turner MR. Public awareness of motor neuron disease. Amyotroph Lateral Scler 2010;11:490-1.

14. O'Brien MR, Whitehead B, Jack BA, et al. From symptom onset to a diagnosis of amyotrophic lateral sclerosis/motor neuron disease (ALS/MND): experiences of people with ALS/MND and family carers —a qualitative study. Amyotroph Lateral Scler 2011;12:97-104.

15. Braun V, Clarke V. Using thematic analysis in psychology. Qual Res Psychol 2006;3:77-101.

16. Karekla M, Panayiotou G. Coping and experiential avoidance: unique or overlapping constructs? J Behav Ther Exp Psychiatry 2011;42:163-70.

17. Kashdan TB, Barrios V, Forsyth JP, et al. Experiential avoidance as a generalized psychological vulnerability: comparisons with coping and emotion regulation strategies. Behav Res Ther 2006;44:1301-20.
18. Chiò A, Montuschi A, Cammarosano S, et al. ALS patients and caregivers communication preferences and information seeking behaviour. Eur J Neurol 2008;15:55-60.

19. Galvin M, Corr B, Madden C, et al. Caregiving in ALS-a mixed methods approach to the study of burden. BMC Palliat Care 2016;15:81

20. Burke T, Elamin M, Galvin M, et al. Caregiver burden in amyotrophic lateral sclerosis: a cross-sectional investigation of predictors. J Neurol 2015;262:2799

21. Lerum SV, Solbraekke KN, Frich JC. Family caregivers' accounts of caring for a family member with motor neurone disease in Norway: a qualitative study. BMC Palliat Care 2016;15:22.

22. Schellenberg KL, Schofield SJ, Fang SF, et al. Breaking bad news in amyotrophic lateral sclerosis: the need for medical education. Amyotroph Lateral Scler Frontotemporal Degener 2014;15:47-54.

23. Chiò A, Borasio GD. Breaking the news in amyotrophic lateral sclerosis. Amyotroph Lateral Scler Other Motor Neuron Disord 2004:5:195-201. 